\title{
Risk to Radiology Staff for Occupational COVID-19 Infection in a High-Risk and a Low-Risk Region in Germany: Lessons from the "First Wave"
}

\section{Risiko radiologischer Mitarbeiter für eine COVID-19-Infektion in einer Hoch- und Niedrigrisikoregion in Deutschland: Lehren aus der "ersten Welle"}

Authors

Thomas Finkenzeller ${ }^{1}$, Stephan Lenhart ${ }^{1}$, Mark Reinwald², Stefan Lüth ${ }^{3}$, Lena Marie Dendl ${ }^{4,8}$, Christian Paetzel ${ }^{1}$, Natasza Szczypien ${ }^{5}$, Frank Klawonn ${ }^{6}$, Alexander Von Meyer ${ }^{7}$, Andreas G. Schreyer ${ }^{8}$

Affiliations

1 Department of Radiology and Neuroradiology, Hospital Weiden, Germany

2 Department of Hematology and Oncology, Brandenburg Medical School Theodor Fontane, Brandenburg a. d. Havel, Germany

3 Clinic for Gastroenterology, Diabetology \& Hepatology, Brandenburg Medical School Theodor Fontane, Brandenburg a. d. Havel, Germany

4 Department of Radiology, Brandenburg Medical School Theodor Fontane, Treuenbrietzen, Germany, Department of Radiology, Johanniter Specialty Clinic Treuenbrietzen, Treuenbrietzen, Germany

5 Institute for Information Engineering, Ostfalia University of Applied Sciences, Wolfenbüttel, Germany

6 Biostatistics, Helmholtz Centre for Infection Research, Braunschweig, Germany

7 Institute for Laboratory Medicine, Medical Microbiology and Technical Hygienics, Munich Municipal Hospital Group, München, Germany

8 Institute for Diagnostic and Interventional Radiology, Brandenburg Medical School Theodor Fontane, Brandenburg a. d. Havel, Germany

Key words

SARS-CoV-2 antibodies, seroprevalence, risk factors, prevention, radiological staff

received 30.11.2020

accepted 09.02.2021

published online 10.03 .2021

Bibliography

Fortschr Röntgenstr 2021; 193: 537-543

DOI 10.1055/a-1393-6668

ISSN 1438-9029

(c) 2021. Thieme. All rights reserved.

Georg Thieme Verlag KG, Rüdigerstraße 14,

70469 Stuttgart, Germany

\section{Correspondence}

Prof. Andreas G. Schreyer

Institute for Diagnostic and Interventional Radiology, Brandenburg Medical School Theodor Fontane, Hochstraße 29, 14770 Brandenburg a. d. Havel, Germany Tel.: $+49 / 3381 / 412600$ Fax: $+49 / 3381 / 412609$ andreas.schreyer@mac.com

\section{ABSTRACT}

Purpose The recent COVID-19 pandemic has resulted in an increasing overload of the medical system. Healthcare workers (HCW) in radiology departments are exposed to a high infection risk similar to HCWs in the ICU or dedicated COVID wards. The goal of our paper is to evaluate the prevalence of $\mathrm{IgG}$ antibody against SARS-CoV-2 among radiology HCWs in two different hospitals and regions in Germany with a low and high COVID-19 prevalence and to compare it to the prevalence in other clinical personnel. Additionally, we assessed the number of radiological procedures performed in patients with a positive PCR test $(C+)$ followed by a short review of the risk for nosocomial infections of radiology HCWs.

Materials and Methods During the first COVID-19 wave between March and July 2020, we evaluated a region with one of the highest COVID-19 rates (776-1570/100 000) in Germany (Hospital A). Additionally, we assessed Hospital B in a region with a low prevalence (65/100000). We tested the serum prevalence of SARS-CoV-2 IgG antibodies among the whole staff with a subgroup analysis for radiology in both hospitals. We calculated the total number of different radiological procedures performed in $\mathrm{C}+$ patients.

Results In Hospital A 594 PCR-proven C+ patients were treated resulting in 2723 radiological procedures. $24 \%(n=6)$ of the radiology technicians and $13.35(n=2)$ of radiologists had a positive IgG test. The rates were similar to positive rates in HCWs in COVID-19 wards and ICUs within the hospital. The most frequently performed procedures in $\mathrm{C}+$ patients were chest X-rays (3.17/patient) and CT examinations (1.15/patient). In Hospital B $50 \mathrm{C}+$ patients were treated, resulting in 
64 radiological procedures. None of the HCWs tested IgG positive. The most frequently performed examinations were also chest X-rays (1.04/patient) and CT (0.2/patient).

Conclusion HCWs in radiology have a high occupational infection risk similar to that of HCWs in ICUs and dedicated COVID wards.

Key Points:

- The risk of acquiring COVID-19 increases with the amount of contact with infected individuals.

- The occupational risk of a SARS-CoV-2 infection for radiology staff is similar to that of nurses and physicians in COVID wards.

- Hygiene concepts and medical resources have to be adapted for further COVID outbreaks.

- Reporting of an occupational disease can be considered in the case of seropositive staff.

\section{Citation Format}

- Finkenzeller T, Lenhart S, Reinwald M et al. Risk to Radiology Staff for Occupational COVID-19 Infection in a HighRisk and a Low-Risk Region in Germany: Lessons from the “First Wave”. Fortschr Röntgenstr 2021; 193: 537-543

\section{ZUSAMMENFASSUNG}

Ziel Durch die aktuelle COVID-19-Pandemie kommt es stellenweise zu einer Überlastung des Gesundheitssystems. Analog zu den Mitarbeitern im Gesundheitswesen (Healthcare workers, HCW) auf Intensiv- oder COVID-Stationen ist auch das Personal in der Radiologie durch häufigen direkten Kontakt mit infektiösen Patienten einem hohen Infektionsrisiko ausgesetzt. Ziel unserer Arbeit war es, an 2 Klinikstandorten in Deutschland mit jeweils hoher bzw. geringer Prävalenz von COVID-19 in der Bevölkerung die Seroprävalenz von IgG-Antikörpern (AK) gegen SARS-CoV-2 bei radiologischem Personal zu evaluieren und in Bezug zum übrigen Klinikpersonal zu setzen. Zusätzlich sollten die Anzahl verschiedener radiologischer Untersuchungen der COVID-19-positiven Patienten $(C+)$ ausgewertet werden und ein Überblick über das Risiko einer berufsbedingten Infektion des radiologischen Personals mit COVID-19 erfolgen.

Material und Methoden Die Auswertung erfolgte nach der ersten Welle der COVID-19-Pandemie zwischen März und Juli 2020 in einer Region mit einer der höchsten Prävalenzen (776-1570/100 000) in Deutschland (Klinikum A). Zusätzlich wurde das Klinikum B in einem Gebiet mit niedriger Prävalenz (65/100 000) evaluiert. An beiden Kliniken wurde die IgGSeroprävalenz des gesamten Personals bestimmt und eine Subgruppenanalyse der Radiologie der beiden Standorte vorgenommen. Die Anzahl der mittels PCR gesicherten COVID19-Patienten sowie deren radiologische Untersuchungen wurde erfasst.

Ergebnisse Am Klinikum A waren nach insgesamt 2723 radiologischen Patientenkontakten bei 594 C+-Patienten 24\% $(n=6)$ der medizinisch-technischen Mitarbeiter und 13,3\% $(n=2)$ des ärztlichen Personals der Radiologie IgG-positiv. Dies entsprach den Positivraten der HCW auf COVID- bzw. Intensivstationen des Klinikums. Am häufigsten wurden bei C+-Patienten konventionelle Thoraxaufnahmen (3,17/Patient) und CT-Untersuchungen(1,15/Patient) durchgeführt. Am Klinikum B mit 50 C+-Patienten und 64 Gesamtkontakten lag bei keinem Mitarbeiter der Radiologie ein positiver Antikörpertest vor. Am häufigsten wurden ebenfalls konventionelle Thorax- (1,04/Patient) und CT-Untersuchungen (0,2/Patient) durchgeführt.

Schlussfolgerung Mitarbeiter der Radiologie haben ein ähnlich hohes Risiko, sich mit COVID-19 zu infizieren, wie Mitarbeiter auf COVID- bzw. Intensivstationen.

\section{Introduction}

With millions of people infected globally and a severe disease course in some cases, coronavirus disease 2019 (COVID-19) caused by SARS coronavirus 2 (SARS-CoV-2) has been overloading the health care systems of many countries since the end of 2019[1]. Protecting patients and health care workers (HCWs) against infection with the virus during treatment was and continues to be a difficult task during the ongoing pandemic. Radiology personnel are on the front lines of the response to the COVID-19 pandemic and are at increased risk of infection due to their significant contact with infected and potentially infectious patients in the course of performing their occupational duties. The virus can be transmitted by patients as well as from HCW to HCW and via contact surfaces or aerosols [2].

The seroprevalence of antibodies to SARS-CoV-2 allows conclusions regarding a prior COVID-19 infection [3, 4] and makes it possible to identify risk areas within the diagnostic routine. As a result, workflows and precautionary measures can be optimized and transmission within the hospital can be minimized [5].

Like physicians and HCWs working in wards, radiology employees in the clinical routine have direct contact with infected patients. However, in contrast to HCWs providing inpatient care, direct patient contact of radiology staff can be determined relatively exactly even retrospectively based on the documented radiological examinations of COVID-19-positive patients.

To evaluate the risk to radiology staff (administrative staff, technicians, physicians) posed by direct contact with COVID-19-positive patients, we evaluated the data from two hospital groups in regions of Germany affected to varying degrees by the COVID-19 pandemic. The hospitals tested a majority of their personnel multiple times for the seroprevalence of antibodies to SARS-COV-2 and analyzed the data in relation to individual work areas and departments in the hospital. The data from one hospital group in the region of the northern Upper Palatinate (Southeast Germany) with the highest infection rate (up to 1570 cases/100 000 inhabitants) was evaluated. The radiology department in a region in northeastern Ger- 
many (Brandenburg) with a lower infection rate (65/100 000) was examined as a control group. The goal of the study was to evaluate the probable prior infection of radiology staff during the first wave of the COVID pandemic and to compare the data to direct patient contact corresponding to radiological examinations of COVID-19positive patients.

\section{Materials and Methods}

\section{Study locations}

We analyzed the antibody status and clinical symptoms of COVID-19 disease of radiology personnel as part of an ongoing study of hospital personnel at two locations in Germany affected to varying degrees by the COVID-19 pandemic.

\section{Study region - hospital A (southeast Germany) - high prevalence}

Hospital A (774 beds at 2 locations) represents the situation in a high-risk region for COVID-19. The hospital provides care for approximately 280000 inhabitants of a region of Germany in a rural area in northeast Bavaria with a high prevalence of COVID-19 between March and July 2020 [6]. This region includes the county Tirschenreuth (1570 cases/100000 inhabitants) as well as the counties Wunsiedel (909/100000) and Neustadt/Waldnaab (860/ 100000 ), which were ranked 3 and 4 in the prevalence statistics of the RKI (Robert Koch Institute) in July 2020. The city Weiden as the site of the main hospital (796/100 000) was ranked 7 Germanywide in July 2020 prior to the first German coronavirus hotspot in Heinsberg (776/100 000) [7]. In the health care facilities of this region, more than 1450 patients with suspected COVID-19 were treated on an inpatient basis between March and July 2020. SARSCoV-2 infection was confirmed via PCR in 594 of these patients ( Table 1).

\section{Study region - hospital B (northeast Germany) - low prevalence}

Hospital B is a health care provider for approximately 177000 inhabitants in northeastern Germany (Brandenburg). Only 65 positive COVID-19 cases were identified in the study period up to July 2020 at the control hospital. From March to July, only 50 patients with PCR-confirmed SARS-CoV-2 infection from the entire region were treated on an inpatient basis at hospital B (566 beds).

\section{Radiology departments at hospitals A and B}

The radiology department at hospital $A$ is comprised of 16 physicians, 29 radiology technicians at 2 locations and 5 staff members in the administrative office ( $\triangleright$ Table 2). One CT unit is installed at the main site of hospital A (649 beds) and one at the second site (145 beds). The numbers were similar at control hospital $B$ with 10 physicians and 28 radiology technicians. Hospital $B$ is also equipped with similar equipment with the exception of having 2 CT scanners at one location.
- Table 1 Aggregation of key data describing the two different regions in Germany for hospital A (high prevalence) and hospital B (low prevalence) regarding the COVID-19 pandemic during the study period from March to July 2020.

\begin{tabular}{|l|l|l|}
\hline & $\begin{array}{l}\text { hospital A } \\
\text { Southeast } \\
\text { Germany } \\
\text { high } \\
\text { prevalence }\end{array}$ & $\begin{array}{l}\text { hospital B } \\
\text { Northeast } \\
\text { Germany } \\
\text { low } \\
\text { prevalence }\end{array}$ \\
\hline state & Bavaria & Brandenburg \\
\hline $\begin{array}{l}\text { number of people receiving } \\
\text { care (n) }\end{array}$ & 280000 & 177000 \\
\hline $\begin{array}{l}\text { COVID-19 cases/100 000 in } \\
\text { the region serviced by the } \\
\text { hospital }\end{array}$ & $776-1570$ & 65 \\
\hline $\begin{array}{l}\text { PCR-confirmed COVID-19 } \\
\text { cases at the hospital }\end{array}$ & 594 & 50 \\
\hline
\end{tabular}

- Table 2 Aggregation of key data characterizing the two evaluated radiological departments at hospital A (high prevalence) and hospital $\mathrm{B}$ (low prevalence) regarding radiological equipment and staff during the study period from March to July 2020.

\begin{tabular}{|l|l|l|}
\hline modalities & hospital A & hospital B \\
\hline CT & 2 & 2 \\
\hline & $\begin{array}{l}\text { (at two } \\
\text { locations) }\end{array}$ & \\
\hline MRI & 2 & 2 \\
\hline angiography & 2 & 1 \\
\hline conventional stationary and mobile & 7 & 7 \\
\hline X-ray machines & & \\
\hline personnel & 16 & 10 \\
\hline physicians & 15 & 10 \\
\hline those tested for antibodies & 29 & 28 \\
\hline radiological technicians & 25 & 28 \\
\hline those tested for antibodies & 5 & 4 \\
\hline administrative staff & 5 & \\
\hline those tested for antibodies & & \\
\hline
\end{tabular}

\section{Hygiene concepts at both locations}

At the start of the pandemic in Germany, there were no clear guidelines and regulations regarding interaction with infected patients and the protection of employees. Beginning in March, all employees at hospital $A$ with patient contact were advised to protect themselves from infection with the SARS-CoV-2 virus by wearing personal protective equipment (PPE). In radiology, all employees were required to wear mouth and nose protection beginning on 3/9/2020. In the case of examination of patients with suspected COVID or confirmed infection (COVID+), the wearing of FFP2 masks (filtering face piece) was mandatory, provided 
that such masks were available. In CT and angiography, additional wearing of goggles or face shields was advised to provide greater protection. The use of disposable gowns and disposable gloves was mandatory in the case of direct contact with patients. Due to the rapid increase in cases within one week in mid-March, it was not possible to assign personnel to various teams or to individual radiology modalities. This situation was further aggravated by disease and suspected cases among radiology personnel.

COVID and COVID+ patients were examined using X-ray equipment set up specifically for them. Since only one CT scanner was available at each of the two sites of hospital $A$ at the time of the pandemic, an attempt was made to minimize CT examinations among these patients if clinically feasible. However, this was only possible to a limited extent due to the high number of patients and the small number of available PCR tests. Some PCR tests were also negative in spite of clear symptoms of an infection so that CT had to be used for further workup of the infection. The units had to be wiped with disinfectant after every examination of these patients. MRI examinations of COVID patients were always performed on the same scanner. The second unit was reserved for non-infected patients.

Similar hygiene measures were implemented at hospital B. Since two CT units were in operation there, one scanner was dedicated to the examination of COVID+ patients. In addition, an attempt was made in accordance with organizational recommendations for radiology $[8,9]$ to prevent mixing of radiology personnel between different devices and modalities.

\section{Analysis of radiological examinations of COVID-positive patients}

For our study, we examined all patients with a COVID-19 infection confirmed by PCR test and treated between 3/1/2020 and 6/30/ 2020 at hospitals A and B. All patients with PCR test during their inpatient stay were identified at both hospitals and the number of radiological examinations of these patients was recorded. An anonymized and cumulative list was compiled to show how many conventional radiological examinations, CT examinations, MRI examinations, and angiography examinations were performed. Since sonographic examinations of COVID+ patients were performed by the treating physician in the wards at hospital $A$ in the high-risk region in order to minimize patient transport to the radiology department, this data could not be evaluated retrospectively.

\section{Evaluation of the antibodies of medical personnel}

In the last two weeks of July 2020, blood samples were collected from the employees of the radiology departments at both hospitals in accordance with the guidelines of good clinical practice (GCP) according to the Declaration of Helsinki. Evaluation was performed as part of testing of the entire hospital staff for SARSCoV-2 antibodies. Participation was voluntary. The data was pseudonymized. The ethics committee approved the scientific evaluation of the results and the examined employees provided written informed consent (hospital A: number of the Bavarian State Chamber of Physicians 20 043; hospital B: E-01-20 200 409).

Blood was collected from the participants in a standardized manner. Hospital A used the immunoassay Elecsys ${ }^{\circledR}$ Anti-SARS-
CoV-2 test (Roche Diagnostics, Germany) to test for combined IgM and IgG antibodies, while hospital B used Euroimmun AntiSARS-CoV-2-ELISA (Euroimmun Medizinische Labordiagnostika, Lübeck, Germany) to test for the presence of IgG and IgA antibodies. Due to the limited specificity of $\lg A$ antibodies in coronaSARS-CoV2 infection $[10,11]$, the results of the combined $\mathrm{IgM} /$ $\operatorname{lgG} / \lg A$ test (hospital A) and the separate $\lg G$ and $\lg A$ tests (hospital B) were evaluated to ensure the comparability of the results of both hospitals.

In addition, a questionnaire was provided to each employee to evaluate whether and to what extent each participant had experienced typical clinical symptoms of a COVID-19 infection.

\section{Results}

\section{COVID-19-positive patients}

At hospital A, a total of 1450 patients with COVID or suspicion of COVID were treated on an inpatient basis between March and June 2020. 594 had positive PCR result. The first patient was admitted on an inpatient basis on 3/4/2020 ( $\triangleright$ Table 3).

At hospital B, a total of 50 PCR-positive COVID-19 patients were treated on an inpatient basis in the study period. The first positive patient was admitted on an inpatient basis on 3/30/2020.

\section{Radiological examinations of PCR-positive patients}

A total of 2723 examinations of 594 PCR-positive COVID-19 patients were performed by radiology personnel at hospital $A$ in the study period ( $\vee$ Table 3 ). On average at hospital A, 3.17 conventional X-ray examinations $(n=1885)$ were performed per patient, 1.15 CT examinations ( $n=683), 0.25$ MRI examinations $(n=149)$, and 0.01 angiography examinations (DSA) $(n=6)$. Ultrasound examinations of COVID-19 or COVID+ patients were performed primarily by the treating department in the ward to minimize the transport of patients within the hospital. Therefore, no statistical evaluation can be performed here.

At hospital B, 50 PCR-positive COVID-19 patients were admitted on an inpatient basis in the study period and only 1.28 radiological examinations were performed per patient. Conventional chest X-ray was performed most frequently $(n=64)$ with an average of 1.04 examinations per patient followed by CT examinations $(n=10)$ with an average of 0.2 examinations per patient.

\section{Antibody prevalence among employees}

The antibody prevalence of the entire hospital staff ( $n=277$ ) 1838) at hospital A including hospital administration was $15.1 \%$ in July 2020 (95\% confidence interval (CI): 13.4-16.7\%), with $20.0 \%$ being among the nursing staff and $12.0 \%$ among the physicians. $60 \%$ of the seropositive employees stated that they had lost their sense of taste and/or smell in the last 3 months. $36.6 \%$ experienced trouble breathing, $34.4 \%$ had fever, and $28.6 \%$ reported a general feeling of weakness. Only approximately $20 \%$ experienced a cough and a sore throat.

The subgroup analysis for radiology showed that a total of $84.9 \%(45 / 53)$ of the radiology personnel at hospital A had been tested. $17.8 \%$ were seropositive for SARS-CoV-2 antibodies. Radi- 
- Table 3 Contact of COVID-19-positive patients with radiology and evaluation of different examination modalities in both hospitals (study period from March to July 2020).

\begin{tabular}{|c|c|c|c|c|}
\hline \multirow[b]{2}{*}{ beds at the hospital } & \multicolumn{2}{|c|}{ hospital A } & \multicolumn{2}{|c|}{ hospital B } \\
\hline & 774 & & 566 & \\
\hline $\begin{array}{l}\text { day of admission of the first COVID-19-positive } \\
\text { patient }\end{array}$ & & $3 / 4 / 2020$ & & $3 / 30 / 2020$ \\
\hline COVID-19-positive patient contact with radiology & & $\begin{array}{l}\text { contact/images per COVID-19- } \\
\text { positive patient }\end{array}$ & & $\begin{array}{l}\text { contact/images per COVID-19- } \\
\text { positive patient }\end{array}$ \\
\hline total number of times contact occurred & 2723 & 4.58 & 64 & 1.28 \\
\hline X-ray & 1885 & 3.17 & 52 & 1.04 \\
\hline CT & 683 & 1.15 & 10 & 0.2 \\
\hline MRI & 149 & 0.25 & 0 & 0 \\
\hline angio (DSA) & 6 & 0.01 & 0 & 0 \\
\hline ultrasound & $\mathrm{N} / \mathrm{A}$ & $\mathrm{N} / \mathrm{A}$ & 2 & 0.04 \\
\hline radiologists & 15 & & 10 & \\
\hline physicians who tested positive for antibodies (lgG) & 2 & $13.3 \%$ & 0 & $0.0 \%$ \\
\hline radiological technicians & $25^{*}$ & & 30 & \\
\hline $\begin{array}{l}\text { radiological technicians who tested positive for } \\
\text { antibodies }(\mathrm{lg} G)\end{array}$ & 6 & $24.0 \%$ & 0 & $0.0 \%$ \\
\hline radiological administrative/clerical staff & 5 & & 4 & \\
\hline $\begin{array}{l}\text { administrative staff who tested positive for } \\
\text { antibodies (IgG) }\end{array}$ & 0 & $0.0 \%$ & 0 & $0.0 \%$ \\
\hline
\end{tabular}

ology technicians were most affected (24\%; 6/25). 5 of those infected had clear symptoms including fever and cough and 4 also lost their sense of smell. Due to their symptoms, they quarantined until they were symptom-free and could present two negative PCR tests. One employee did not notice any symptoms and also did not receive a PCR test. 13.3 \% (2/15) of the radiologists at hospital A tested positive for antibodies. Both of them had typical COVID symptoms including high fever, loss of the sense of smell, loss of appetite, and abdominal symptoms.

By July 1, 2020 at hospital B, the antibody prevalence for antiSARS-CoV2 IgG for the entire hospital was only $2.1 \%$ (Cl: $1.2 \%$ to $3.8 \%$ ) (13/585 employees). Employees who tested positive most frequently experienced headache $(50 \%)$ followed by fatigue $(42 \%)$, dyspnea (33\%), and an unproductive cough ( $25 \%$ ). Only one employee who tested positive experienced loss of taste or smell (8\%).

For the subgroup analysis of radiology employees $(n=42)$, none tested positive for anti-SARS-CoV-2 IgG (0\%).

\section{Discussion}

Due to the greater exposure to infected persons, HCWs must be classified as a high-risk group for infection with SARS-CoV-2 [12]. Primarily activities performed close to the patient, such as intensive care and physiotherapy, and also frequent and close patient contact as in radiology potentially result in high infection rates of hospital personnel. A long-lasting coronavirus wave can result in a loss of regional control of the medical management of the pandemic [13]. Infection rates from Italy and Spain showed a cumulative prevalence for SARS-CoV-2 among HCWs of 9-38\% [14, 15].

\section{Occupational risks}

Greater prevalence of COVID-19 in a region increases the individual risk of infection primarily due to transmission in private and public life $[16,17]$.

In addition to their personal risk, HCWs have a significantly higher occupational risk of infection that increases with greater contact with infected persons $[13,18]$.

In radiology, contact of individual employees with COVID+ patients can be tracked relatively precisely by evaluating the examinations that were performed. In comparison to other areas in the 
hospital and to other affected regions, this allows good stratification of the risk posed to radiology personnel. Direct patient contact and close physical proximity to infected persons, e. g. in the case of conventional chest $X$-rays at the patient bedside, CT examinations, rectal or oral contrast enhancement, and interventions, are recognized as risk factors for occupational infection with SARS-CoV-2 [19]. In the study at hospital A, 988 employees at a neighboring non-medical business were examined as the control group to determine the infection risk for regional workers in order to be able to better assess the infection risk of people in the region in private life. The seroprevalence for SARS-CoV-2 antibodies at the company was highly significantly lower (3.7\%; p>0.0001) than among hospital personnel (15.1\%) [20]. Based on this data, it is possible to approximate the private risk compared to the occupational infection risk in the particular region. Of course, a clear allocation of the particular infection site is not possible.

The fact that radiology technicians are more affected than physicians is a further indication that direct contact to patients and a greater number of times of contact additionally increase the risk.

Primarily during the first wave of the COVID-19 pandemic, the lack of knowledge about the disease, the large number of patients in many locations, and the lack of personal protective equipment in some cases resulted in a significantly higher risk for radiology departments at hospitals with a high COVID-19 prevalence. The use of chest X-rays and primarily CT examinations for diagnosis and for follow-up of the disease course results in repeated contact between radiology employees and patients especially during the potentially infectious phase. Infected radiology technicians at hospital A primarily worked in computed tomography prior to becoming infected. However, given the rapid increase in the number of patients at the end of March 2020, it was no longer possible to assign employees to individual modalities. As a result of the high rate of asymptomatic people and a relatively long incubation period, it can no longer be retrospectively clarified where the personnel became infected.

Among the HCWs in this study, $10.1 \%$ of all seropositive employees did not experience any typical COVID-19 symptoms. Asymptomatic employees can be potential spreaders within their own department so that transmission from HCW to HCW is also relevant here. Therefore, affected hospitals can be a site of transmission or further transmission of the virus both for patients and for the hospital's own personnel even if all hygiene regulations are observed [12].

\section{Recognition of COVID-19 as an occupational disease}

Given the risk of occupationally acquired infection with SARS-CoV-2 with potential long-term effects, COVID-19 infection can be recognized as an occupational disease for employees in the health care industry [21] and guidelines for testing HCWs have been developed $[22,23]$. By September 2020, almost 19000 cases of occupational disease in connection with COVID-19 had been reported to the statutory accident insurance companies in Germany. Approximate- ly $43 \%$ of these cases had already been recognized at this time. In the case of occupational contact with SARS-CoV-2, corresponding symptoms of the disease, and a positive PCR test result, employees should consider reporting the justified suspicion of an occupational disease to the responsible statutory accident insurance company [24]. Since the risk for employees in radiology departments seems to be similarly high as for those working in COVID wards or in the ICU, protection of these employees must be given highest priority. Persons infected in the course of performing their occupational duties should be notified of the possibility of reporting their infection to their employer or medical officer since the long-term effects of a SARS-CoV-2 infection are still unclear.

\section{Limitations of the study}

Data was collected over a period of 4 weeks. Due to the relatively rapidly spread of the infection, an exact date for the point prevalence of seropositivity cannot be specified. Instead, the period from the end of June to the end of July 2020 is used for analysis. However, the study still provides sufficiently accurate data regarding the first surge of the pandemic in Germany based on the examined time period from March to July 2020. The method does not allow differentiation of private sources of infection from cases of nosocomial transmission. Unfortunately, this problem affects almost all studies regarding this topic. The highly significant increase in the infection rate of HCWs at hospital A compared to individuals in the same region working in the non-medical sector makes it possible to at least classify the risk posed by working at a hospital. However, exact determination of the particular infection site of affected individuals remains speculative. Unfortunately, it is not possible to retrospectively differentiate the risks for radiology staff based on area of operation due to the complexity of processes and the numerous possibilities for infection during the daily routine. Finally, the use of two different antibody tests at the two evaluated hospitals must be mentioned as a study limitation. However, since the information provided by the manufacturer regarding sensitivity and specificity differs only slightly, this should not have a relevant effect on our analysis.

\section{Conclusion}

The risk of a SARS-CoV-2 infection is as high for radiology staff as for nurses and physicians in dedicated COVID-19 wards or in the ICU. The risk increases with the regional prevalence of disease and the number of times of contact with persons infected with COVID-19. It is extremely important to observe hygiene regulations and to ensure personal protection of employees during the pandemic, particularly in high-risk regions. The long-term effects of occupationally acquired SARS-CoV-2 have not yet been determined. Those affected should be advised to report an occupational infection as a potential occupational disease. Workflows and hygiene concepts adapted to the situation at each particular hospital are needed for further waves of the infection. 


\section{CLINICAL RELEVANCE}

- The risk of an occupational SARS-CoV-2 infection is similarly high for radiology personnel in high-risk regions as for nurses and physicians in COVID wards.

- Hygiene concepts and resources in radiology must be optimized for further waves of infection.

- For SARS-CoV-2 seropositive employees in the health care industry, recognition of the infection as an occupational disease can be considered.

\section{Conflict of Interest}

The authors declare that they have no conflict of interest.

\section{References}

[1] Onder G, Rezza G, Brusaferro S. Case-Fatality Rate and Characteristics of Patients Dying in Relation to COVID-19 in Italy. JAMA 2020; 323: 17751776. doi:10.1001/jama.2020.4683

[2] Chia AQX, Cheng LT, Wijaya L et al. Chest Radiographs and CTs in the Era of COVID-19: Indications, Operational Safety Considerations and Alternative Imaging Practices. Acad Radiol 2020; 27: 1193-1203. doi:10.1016/ j.acra.2020.06.022

[3] Felice C, Di Tanna GL, Zanus G et al. Impact of COVID-19 Outbreak on Healthcare Workers in Italy: Results from a National E-Survey. J Community Health 2020; 45: 675-683. doi:10.1007/s10900-020-00845-5

[4] Garcia-Basteiro AL, Moncunill G, Tortajada M et al. Seroprevalence of antibodies against SARS-CoV-2 among health care workers in a large Spanish reference hospital. Nat Commun 2020; 11: 3500. doi:10.1038/ s41467-020-17318-x

[5] Wong ASK, Ooi CC, Leow MQH et al. Adapting Lessons From SARS for the COVID-19 Pandemic-Perspectives From Radiology Nursing in Singapore. J Radiol Nurs 2020; 39: 164-167. doi:10.1016/j.jradnu.2020.06.008

[6] [Anonym]. https://www.destatis.de/DE/Themen/Laender-Regionen/ Regionales/_inhalt.htm. In: Statistisches Bundesamt 2020

[7] [Anonym]. Am stärksten betroffene Landkreise COVID-19/100.000 Einwohner (23.07.2020). In: RKI (Robert Koch-Institut) 2020

[8] SAGW J. How I do it - SARS-CoV-2: Organisationsempfehlungen für radiologische Abteilungen. Radiologie up2date 2020; 20: 108-110. doi:10.1055/a-1076-3399

[9] Antoch G, Urbach H, Mentzel H] et al. SARS-CoV-2/COVID-19: Empfehlungen fur die Radiologische Versorgung. Rofo 2020; 192: 418-421. doi:10.1055/a-1149-3625
[10] Horvath K, Semlitsch T, Jeitler K et al. [Antibody tests for COVID-19: What the results tell us]. Z Evid Fortbild Qual Gesundhwes 2020; 153: 54-59. doi:10.1016/j.zefq.2020.05.005

[11] Pecora ND, Zand MS. Measuring the Serologic Response to Severe Acute Respiratory Syndrome Coronavirus 2: Methods and Meaning. Clin Lab Med 2020; 40: 603-614. doi:10.1016/j.cll.2020.08.014

[12] Xiao ], Fang M, Chen Q et al. SARS, MERS and COVID-19 among healthcare workers: A narrative review. J Infect Public Health 2020; 13: 843848. doi:10.1016/j.jiph.2020.05.019

[13] Bielicki JA, Duval X, Gobat N et al. Monitoring approaches for health-care workers during the COVID-19 pandemic. Lancet Infect Dis 2020; 20: e261-e267. doi:10.1016/S1473-3099(20)30458-8

[14] Folgueira MD, Munoz-Ruiperez C, Alonso-Lopez MA et al. SARS-CoV-2 infection in Health Care Workers in a large public hospital in Madrid, Spain, during March 2020. In 2020 doi:10.1101/2020.04.07.20055723

[15] Sanità ISd. Sorveglianza integrata COVID-19: I principali dati nazionali. In 2020 March 11

[16] Liu Y, Gayle AA, Wilder-Smith A et al. The reproductive number of COVID-19 is higher compared to SARS coronavirus. J Travel Med 2020; 27: doi:10.1093/jtm/taaa021

[17] Streeck H, Schulte B, Kummerer BM et al. Infection fatality rate of SARS CoV2 in a super-spreading event in Germany. Nat Commun 2020; 11 : 5829. doi:10.1038/s41467-020-19509-y

[18] Koh WC, Naing L, Chaw L et al. What do we know about SARS-CoV-2 transmission? A systematic review and meta-analysis of the secondary attack rate and associated risk factors. PLoS One 2020; 15: e0240205. doi:10.1371/journal.pone.0240205

[19] Zhang S, Diao MY, Duan L et al. The novel coronavirus (SARS-CoV-2) infections in China: prevention, control and challenges. Intensive Care Med 2020; 46: 591-593. doi:10.1007/s00134-020-05977-9

[20] Finkenzeller T, Faltlhauser A, Dietl KH et al. [SARS-CoV-2 antibodies in ICU and clinic staff: From Germany's region with the highest infection rate]. Med Klin Intensivmed Notfmed 2020; 115: 139-145. doi:10.1007| s00063-020-00761-5

[21] Moehner M, Wolik A. Differences in COVID-19 risk between occupational groups and employment sectors in Germany. Dtsch Arztebl Int 2020; 117: 641-642. doi:10.3238/arztebl.2020.0641

[22] AWMF, (DIVI) DIVfl-uNeV. SARS-CoV-2 Infektion bei Mitarbeiterinnen und Mitarbeitern im Gesundheitswesen - Bedeutung der RT-PCR Testung. In: AWMF ed 2020: S1-Leitlinie

[23] Black JRM, Bailey C, Przewrocka J et al. COVID-19: the case for healthcare worker screening to prevent hospital transmission. Lancet 2020; 395: 1418-1420. doi:10.1016/S0140-6736(20)30917-X

[24] Hilienhof A. COVID-19: Knapp 19000 Berufskrankheiten angezeigt. Dtsch Arztebl Int 2020; 117: A1956 